\title{
Analysis of Elevators Dynamic Parameters with Solution of Summary Data Acquisition During Experimental Research
}

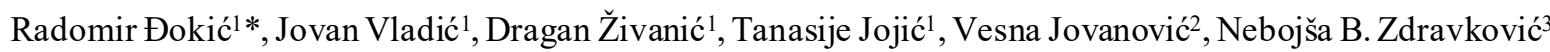 \\ ${ }^{1}$ Faculty of Technical Sciences, University of Novi Sad, Serbia \\ ${ }^{2}$ Faculty of Mechanical Engineering, University of Niš, Serbia \\ ${ }^{3}$ Faculty of Mechanical and Civil Engineering in Kraljevo, University of Kragujevac, Serbia
}

\begin{abstract}
Modelling of the dynamic behaviour of elevators with high lifting velocities (contemporary elevators in building construction and mine elevators) is a complex task and an important step in the design process and creating conditions for safe and reliable exploitation of these machines. Due to high heights and lifting velocities, the standard procedures for dynamic exploitation are not adequate. With the purpose of identifying the basic parameters of the dynamic model (stiffness and damping), a unique method was applied, based on experimental measures for a concrete elevator. Due to the verification of this procedure, the experiment was conducted on a mine elevator in RTB Bor, Serbia. Simulations of the dynamic behaviour of an empty and loaded cage are presented using the obtained computational-experimental results.
\end{abstract}

\section{Keywords: Mechanical characteristics of steel ropes, Data acquisition, Experimental research}

\section{INTRODUCTION}

The elevator quality is estimated according to several important indicators. Safety, comfort, and reliability are especially important features [1]. These indicators depend on, first of all, vibrations occurring while the elevator is in motion. Vibrations are a consequence of driving parameters, inertial characteristics and elasticity of the binding elevator elements.

Judging by the dynamic impact on the vibration values, an elevator can be divided into two basic parts. The first part is a driving mechanism (engine, reductor, brake, and couplings), while the second part is a cabin lifting system, mostly made of steel ropes for lifting the counterweights on one end and cabin (cage) on the other end and their guide rails. The driving mechanism comprises elements that are much more rigid and have smaller mass compared to the cabin lifting system, which in turn causes the oscillations in smaller amplitudes and higher frequencies. As well as that, bearing in mind the oscillations are indirectly transferred to the cabin (cage), via ropes, it can be deduced that the lifting system has a much bigger influence on the comfort during the motion than driving mechanism elements does.

While the elevator is in operation mode, the hoist ropes increase and decrease their free length, so the parameters, such as rope stiffness and damping are constantly being changed [2] and [3]. In high-speed elevators, a dynamic instability may occur during lifting (reduction of free length), due to an increase in relative deformation. This seriously impacts the safety of the passengers. Since classic models are based on elastic body (rope) oscillations with constant dynamic parameters (mass, stiffness and damping), it is necessary to form such dynamic models that will enable the analysis and definition of the dynamic behavior of elevators with variable parameters [4] and [5].

Due to the fact that special attention has to be paid to the accuracy of installing and making of cabin guide rails and counterweight in high-speed elevators, the following conclusion arises. Without the addition of external influences, it can be concluded that longitudinal oscillations are dominant, as opposed to transversal oscillations.

Taking into consideration that up until this moment the problems in driving mechanism vibrations were the subject of a great number of scientific and research papers, with standard analyses as the most frequently applied method, it seems logical that the main focus of elevator dynamic research should be pointed towards innovative methods for analysing the longitudinal oscillations with variable parameters [6].

The mine elevators are used to interconnect different mine horizons by using a mine cage (which is moved between at least two firmly set guide rails), whose dimensions and construction enable ore loading and are approachable to people.

The mines use two systems, one with a drum and the other with a driving pulley (Köepe system). Fig. 1 provides a scheme of the most applied lifting system in mine facilities with a friction mechanism (Köepe system).

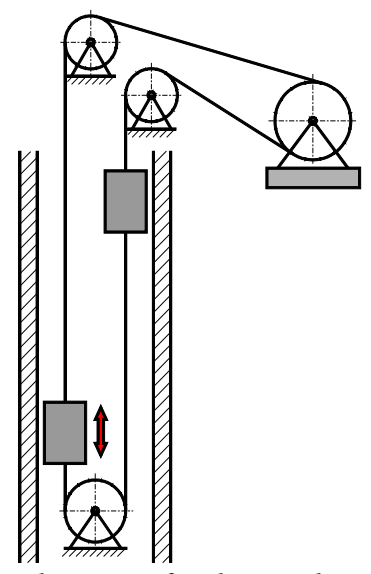

Figure 1: Exploitation facility in the mines with an underground shaft 
In the systems with a lifting drum, the carrying ropes are wound and stored on a drum. The drums are located in the machine room which is usually sideways of the mine shaft, and the ropes go down from it over the deflector pulleys into the shaft next to the cabin.

Friction lifting systems (Köepe) are mostly used in European mines. The drive is set above or sideways to the mine shaft. In the case when it is located sideways (Fig. 1) deflector pulleys are used and they are set above the mine cage (cabin) and the counterweight. The main advantages of the system are decreasing of a driving motor, i.e. necessary torque, a simpler usage of a higher number of steel ropes and the possibility of setting the driving pulley directly above the mine shaft. However, due to the limitations in contact pressure $(1.75 \mathrm{MPa})$ and the limits of slipping $\left(S_{1} / S_{2} \leq 1.4\right)$ between the ropes and the pulley, the advantages are lost, so in practice both systems are applied almost equally.

\section{FORMING A SUITABLE MODEL FOR THE DYNAMIC ANALYSIS OF MINE ELEVATORS}

\subsection{Standard Models}

There has been a large number of researchers interested in studying longitudinal oscillations and their studies have been based on the general theory about the application of oscillation of elastic bars with constant parameters (mass, stiffness, and damping). These are the so-called standard models. Those models are acceptable for analyzing elevators with low lifting velocities and heights. Fig. $2 \mathrm{a}$ and $2 \mathrm{~b}$ show models with one and two degrees of freedom and a rope of constant lengths, represented here as Hook's, i.e. Calvin's body.

A certain improvement has been made with the analysis of high-lift elevators $(\geq 35 \mathrm{~m})$ and low velocities (till $3 \mathrm{~m} / \mathrm{s}$ ) by using the model represented in Fig. $2 \mathrm{c}$. The model represents a bar of a constant length with an equally spreaded mass $q(\mathrm{~kg} / \mathrm{m})$, i.e. it is a model of an elastic body with an unlimited number of degrees of freedom and a concentrated mass at the bottom end as the boundary condition.

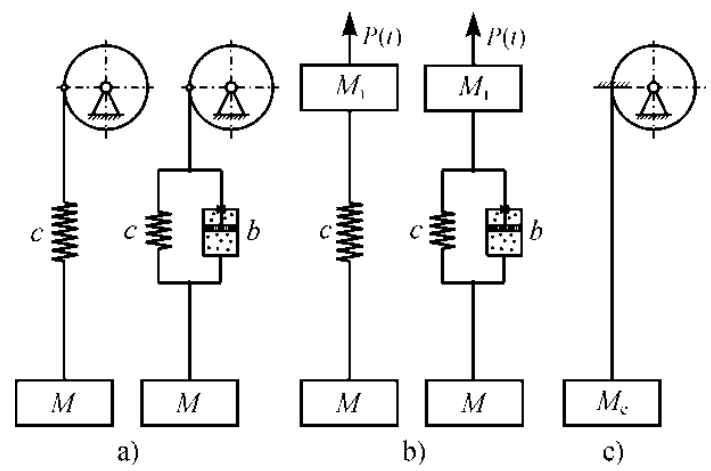

Figure 2: Standard dynamic models; with one degree of freedom (a), with two degrees offreedom (b), and a

"heavy" constant length bar (c)

Based on the analysis which was shown in detail in [7] to [9], in the case when the free rope length is small compared to the cabin mass, it is possible to significantly simplify the dynamic model analysis.

In accordance with the above, when it comes to high-lift elevators and low velocities, it is approximately possible to create load oscillation models with one degree of freedom, with a "heavy" spring, which was studied in general literature. Also, it is necessary to replace the total mass (of both load and rope) with an equivalent mass $M_{\mathrm{e}}=$ $M+(1 / 3) \cdot q L$, reduced in the cabin place, [10] and [11].

\subsection{Dynamic Elevator Models with Variable Dynamic} Parameters

Fig. 3a shows the most common solutions of the lifting systems for high-speed elevators with a driving pulley, while the corresponding dynamic model is shown in Fig. 3b.

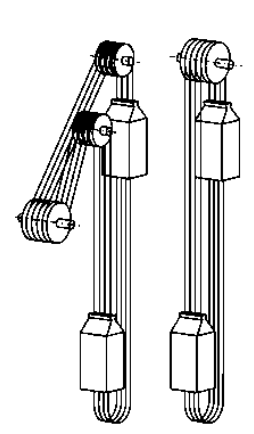

a)

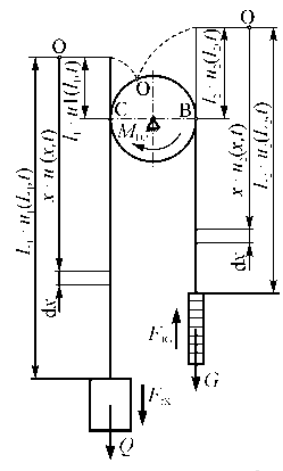

b)

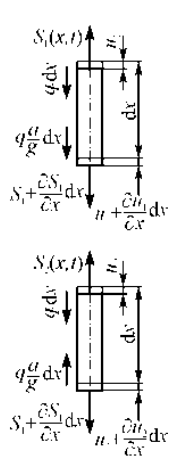

Figure 3: Dynamic model of a high-speed elevator
In order to secure comfort during the motion, control programs are used in contemporary elevators. They define the circumferential velocity of the pulley. Thus, they also define the cabin motion velocity (a kinematic condition), as opposed to the previous period when the motion velocity depended a great deal on the driving electromotor's mechanical characteristics and brake system (the dynamic equilibrium condition). In the earlier periods, a replacement of one-speed engines with twospeed engines was observed as a significant improvement. This bettered the motion comfort in braking instances and aided the accuracy of stopping the cabin. As for the process of a regular elevator, in cases when there is no slipping of the steel rope on the driving pulley and when the driving characteristic is represented via a rope velocity at the meeting point of the rope and pulley, the elevator model can be simplified and represented in the form shown in Fig. 4.

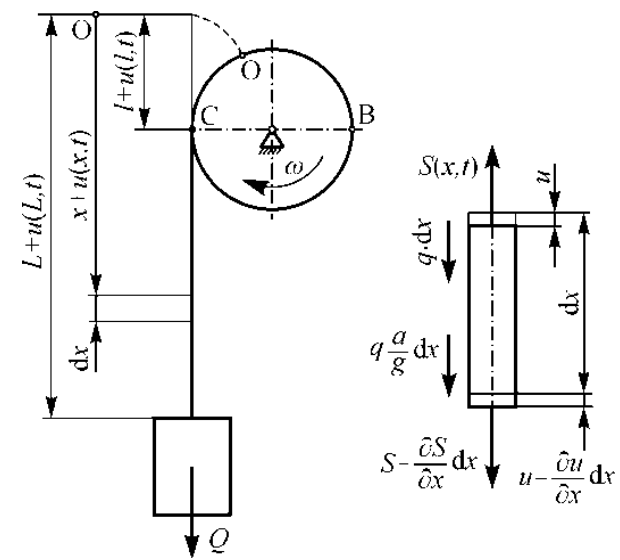

Figure 4: Elevator model with a rope of a variable length with boundary conditions

Upon observing just the upcoming rope end, the model can be represented as a system with an unlimited number of degrees of freedom; at one end it is rolling onto 
the pulley at a $v(t)$ velocity, while on the other it is burdened with concentrated mass. Due to the variable rope length during the motion, the stiffness $(c=E A / L)$ changes . This is a characteristic of parametric oscillations and contributes to the possible occurrence of resonance. To this end, it is necessary to complete certain steps in the analysis of dynamic behavior. One needs to determine the criticallifting velocity, during which the unstable motion occurs, i.e. the rope strain is increased when its free length is reduced.

The deformation of an arbitrary cross-section represents the function of the position $x$, and the time $t$, i.e.:

$$
u=f(x, t)
$$

Upon observing the equilibrium of the elementary part $(d x)$, it can be deduced that:

$$
\frac{q \cdot d x}{g} \cdot \frac{\partial^{2} u(x, t)}{\partial t^{2}}=-S(x, t)+S(x, t)+\frac{\partial S}{\partial x} d x+q \cdot d x \pm \frac{q \cdot d x}{g} \cdot a
$$

By representing the rope as Calvin's model, where the influence of internal friction can be taken into consideration via the so-called rope resistance force factor $\left(b_{\mathrm{f}}\right)$, the dependence of the inner force in the rope on its deformation can be noted in this form:

$$
S(x, t)=E \cdot A \cdot \frac{\partial}{\partial x} \cdot\left[u(x, t)+b_{\mathrm{f}} \cdot \frac{\partial u(x, t)}{\partial t}\right]
$$

If the Eq. (2) is divided with $\frac{q \cdot d x}{g}$ and a replacement for $S(x, t)$, this is obtained:

$$
\frac{\partial^{2} u(x, t)}{\partial t^{2}}=\frac{g \cdot E \cdot A}{q} \cdot \frac{\partial^{2}}{\partial x^{2}}\left(u(x, t)+b_{\mathrm{f}} \cdot \frac{\partial u(x, t)}{\partial t}\right)+g \pm a
$$

By using the differential equation, (Eq. (4)) and the equilibrium condition of moments on the driving pulley, it is possible to form a system of equations that describes a dynamic equilibrium on the driving pulley in the case of a model shown in Fig. $4 \mathrm{~b}$ in this form [12]:

$$
\begin{gathered}
\frac{q}{g} \cdot \frac{\partial^{2} u_{1}(x, t)}{\partial t^{2}}=E \cdot A \cdot \frac{\partial^{2}}{\partial x^{2}} \cdot\left[u_{1}(x, t)+b_{\mathrm{f}} \cdot \frac{\partial u_{1}(x, t)}{\partial t}\right]+q \cdot\left(1 \pm \frac{a}{g}\right) \\
\frac{q}{g} \cdot \frac{\partial^{2} u_{2}(x, t)}{\partial t^{2}}=E \cdot A \cdot \frac{\partial^{2}}{\partial x^{2}} \cdot\left[u_{2}(x, t)+b_{\mathrm{f}} \cdot \frac{\partial u_{2}(x, t)}{\partial t}\right]+q \cdot\left(1 \pm \frac{a}{g}\right)(6) \\
M_{\mathrm{m}}=\frac{R}{i \cdot \eta} \cdot E \cdot A \cdot \frac{\partial}{\partial x}\left\{\begin{array}{l}
u_{1}\left(l_{1}, t\right)-u_{2}\left(l_{2}, t\right)+ \\
+b_{\mathrm{f}} \frac{\partial}{\partial t}\left[u_{1}\left(l_{1}, t\right)-u_{2}\left(l_{2}, t\right)\right]
\end{array}\right\}-J_{\mathrm{r}} \cdot \frac{a \cdot i}{R}
\end{gathered}
$$

with:

$u_{1}, u_{2}$ - elastic deformation of the rope on the incoming and outgoing rope end,

$E$ - rope elasticity modulus,

$A$ - rope's cross-section area,

$a$ - acceleration of the driving mechanism,

$M_{\mathrm{m}}$ - driving motor torque

$i$ - gear ratio,

$\eta$ - driving mechanism efficiency,

$J_{\mathrm{r}}$ - moment of inertia of rotational masses, reduced to the shaft of a driving pulley,

$R$ - driving pulley radius,

$q$ - rope weight per meter.

\section{DYNAMIC PARAMETERS DETERMINATION BY SUMMARY DATA ACQUISITION}

Experimental studies shown in this paper represent the sequel of the research in [8]. The measuring was done on a mine elevator in RTB Bor, Serbia; the maximum projected cage lifting velocity was $16 \mathrm{~m} / \mathrm{s}$ and the projected lifting height was $523 \mathrm{~m}$ in the first phase and $763 \mathrm{~m}$ in the second phase of mining. The driving mechanism is shown in Fig. 5. The other significant characteristics of this exploitation machine can be seen in Tab. 1.

\begin{tabular}{|c|c|}
\hline $\begin{array}{l}\text { Driving } \\
\text { electric motor }\end{array}$ & $\begin{array}{l}\text { Power: } 1500 / 2860 \mathrm{~kW} \text {, number of } \\
\text { revolutions: } 122.2 \mathrm{rpm} \text {, torque: } \\
117.2 / 233.4 \mathrm{kNm}\end{array}$ \\
\hline Cage & $\begin{array}{l}\text { Mass: } 13 \mathrm{t} \text { (it includes the cage } \\
\text { and the connecting tools for } \\
\text { connecting the hoistropes), Fig. } 8\end{array}$ \\
\hline eight & Mass: $21 \mathrm{t}$ \\
\hline Hois & $\begin{array}{l}z=6 \text { pieces, } \\
d=27 \mathrm{~mm} \text { ( } 150 \text { wires per cross } \\
\text { section). } \\
\text { Lang's lay ropes, three right hand } \\
\text { lang's lay ropes, and three left } \\
\text { hand lang's lay ropes. } \\
\text { Breaking force: } 561 \mathrm{kN} \text {, tensile } \\
\text { strength of the wires: } 1700 \mathrm{MPa} \text {. } \\
\text { Unit mass: } 3.02 \mathrm{~kg} / \mathrm{m} \text {. }\end{array}$ \\
\hline $\begin{array}{l}\text { Compensation } \\
\text { ropes }\end{array}$ & $\begin{array}{l}z=2 \text { pieces, } \\
d=50 \mathrm{~mm} \text { ( } 222 \text { wires per cross } \\
\text { section). } \\
\text { Connected with the cage via } \\
\text { rotating hooks to prevent } \\
\text { unwinding. Unit mass: } 9.64 \mathrm{~kg} / \mathrm{m} \text {. }\end{array}$ \\
\hline
\end{tabular}
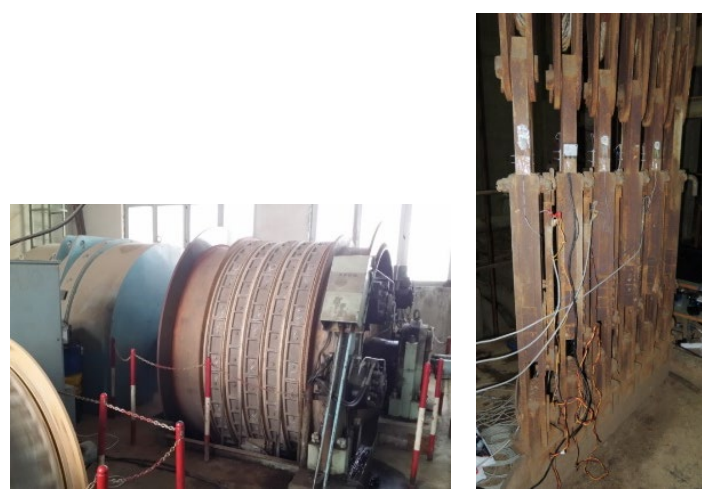

Figure 5: Driving machine of a mine elevator and the connecting tools for connecting the hoist ropes and the cage

Table 1: Mine elevator technical characteristics

A mine shaft is like a round cross-section, with a $10 \mathrm{~m}$ diameter. The transfer of the driving moment to the hoist ropes is done through friction (Köepe system) from the grooved drum with a $2.5 \mathrm{~m}$ diameter.

3.1. Equipment Used and the Method for Measuring Data Acquisition

The following measuring equipment was used for the mine elevator experiment:

- Universal 8-channel measuring amplifier (2 pieces), QUANTUM X MX480B, pos. 10a and 10b (Fig. 6),

- A computer for storing the measuring signals, pos. 13 (Fig. 6),

- Antennas for the wireless transfer of the measuring signal (2 pieces) NanoStation loco NS2L, made by 
IBIQUITI NETWORKS; $5 \mathrm{~km}$ range with the antennas optical visibility, pos. $12 \mathrm{a}$ and $12 \mathrm{~b}$ (Fig. 6),

- Incremental encoder - the number of revolutions sensor AINS 41, made by Meyer Industrie-Electronic GmbH - MEYLE; measuring range up to $6000 \mathrm{rpm}$ and with an allowed axial/radial load at the output shaft of 30/20 N, pos. 9 (Fig. 6),

- Optical measuring device for the number of revolutions ROS type, made by Monarch Instrument; measuring range varies from 1 to $250000 \mathrm{rpm}$, pos. 1 (Fig. 6),

- Accelerometer HBM B12, pos. 2 (Fig. 6),

- Strain gauges HBM LY41-6/120, pos. 3 to 8 (Fig. 6),

- Software for acquisition and processing of measuring signals, HBM catmanEasy-AP.

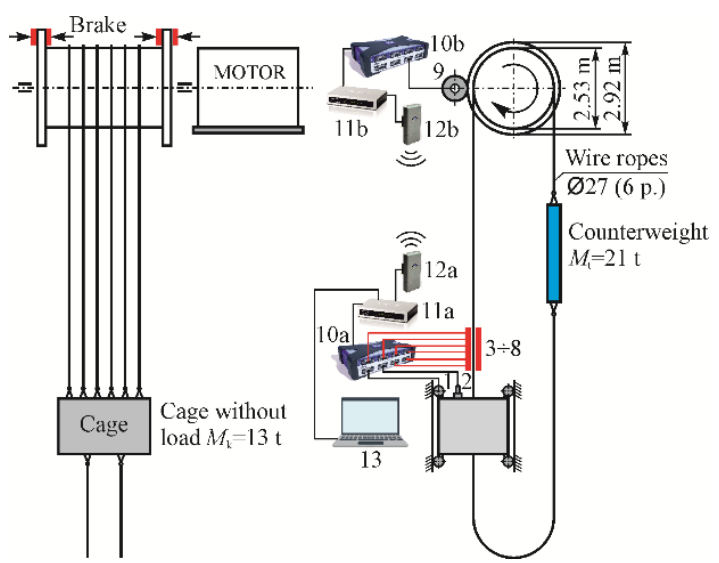

Figure 6: Schematic layout of the measuring places

The experiment was done according to the principle of summary data acquisition via a wireless data transfer, by using the NanoStation loco NS2L antennas (pos. 12a and 12 b, Fig. 6). This way, a complete synchronization of the collected data on the cage roof and machine room was achieved. The drum number of revolutions was measured with an AINS 41 incremental encoder (pos. 9, Fig. 6). It was set on the adaptive carrier with a $127 \mathrm{~mm}$ diameter measuring wheel, which was directly leaned onto the rim of the brake disc, Fig. 7a. The encoder measuring signal was led to the amplifier (pos. 10b, Fig. 6), and then via a LAN switch (pos.11b, Fig 6) and the antenna (pos. 12b, Fig. 6) wirelessly connected to the other radio antenna positioned on the cage (pos. 12a, Fig. 6). The measuring signal was stored in a common computer file (pos. 13, Fig. 6) placed on the cage. It was done via another LAN switch (pos. 11a, Fig. 6).

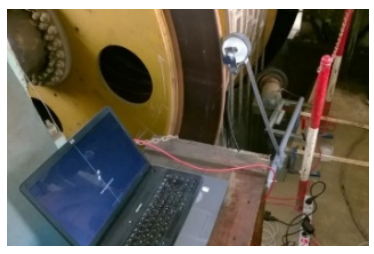

a)

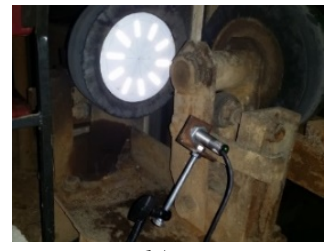

b)
Figure 7: The incremental encoder connected with the measuring wheel positioned on the rim of the brake disc (a), and the optical sensor (number of revolutions sensor) positioned on the cage (b)

The lifting and lowering velocity of the cage was measured via a roller guide, whose change in the number of revolutions was registered with an optical sens or (pos. 1, Fig. 6), positioned on a small magnet table, Fig. 7b. The change in the cage's acceleration during the measuring process was registered by an HBM B12 accelerometer (pos. 2, Fig. 6), set on the connecting tools of the cage through a magnetic holder, Fig. 8a. The force changes in the hoist ropes were monitored by measuring the deformation of the connecting tools (pos. 3 to 8, Fig. 6). The deformations were measured on each connecting tool (out of 6 in total), by using the HBM LY41-6/120 strain gauges, Fig. 8b

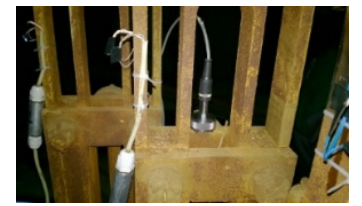

a)

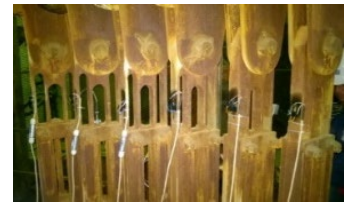

b)
Figure 8: Measurements of acceleration (a) and deformations (b) on the cage connections tools

All measuring signals were led to the other eightchannel measuring amplifier (pos. 10a, Fig. 6) and they were recorded on the computer (pos. 13, Fig. 6) via an LAN switch (pos. 11a, Fig. 6).

\subsection{Results of the Experiment}

Experiment results and determination of the dynamic model parameters in this paper are shown in four characteristic motion cases (lifting and lowering) of the cage, with and without load. A significantly higher number of measurements was completed for different cases (different positions for starting and stopping the cage motion etc.) and the results are presented in [7]. Here, the results of lowering and lifting of an empty cage and a loaded cage (traction machine) are presented.

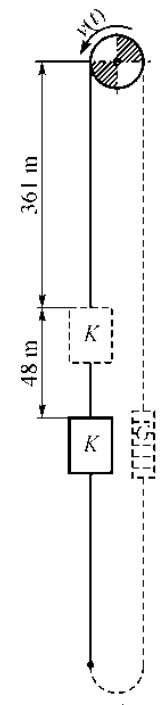

a)

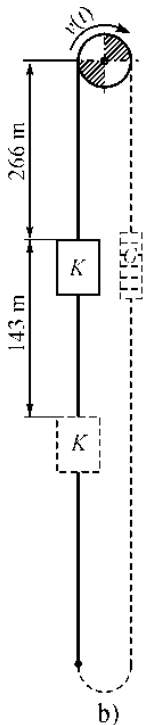

b)

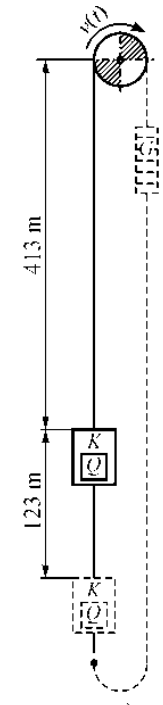

c)

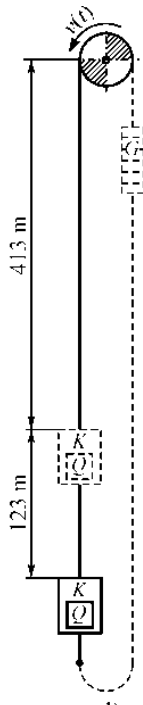

d)
Figure 9: Mine elevator parameters that are relevant for the analysis

According to those, the system oscillation parameters are defined. The characteristics of experimental cases are as follows:

I) Lowering an empty cage from position $+104 \mathrm{~m}$ to position $+56 \mathrm{~m}(48 \mathrm{~m})$. The action of stopping the cage was performed by suddenly switching off the driving electromotor (at a high velocity, Fig. 9a).

II) Lifting of an empty cage from position $+56 \mathrm{~m}$ to a position $+199 \mathrm{~m}(143 \mathrm{~m})$. Stopping the cage was done 
just like in the case above, with the sudden switching off the power to the driving electromotor, at a high velocity, Fig. 9b.

III) Lifting a loaded cage (the traction machine for wagons, mass $\sim 9.35 \mathrm{t}$ ) from position a $-71 \mathrm{~m}$, to position $+52 \mathrm{~m}(123 \mathrm{~m})$. Stopping the cage was done at a low speed, Fig. $9 \mathrm{c}$.

IV) Lowering the loaded cage (the traction machine for wagons, mass $\sim 9.35 \mathrm{t}$ ) from position $+52 \mathrm{~m}$ to $-71 \mathrm{~m}$ $(123 \mathrm{~m})$. Stopping the cage was done at a low speed, Fig. $9 \mathrm{~d}$.

The results of the conducted experimental research can be seen in the following figures, which are showing the changes in the winding velocities of hoist ropes that were wound onto the drum; cage acceleration and changes in the forces in the hoist ropes, i.e. on the elements for connecting the ropes to the cage. The results are valid for all four chosen examples of motion. The diagram shows the character of the changes of the said parameters. It shows the cage oscillation amplitudes that occur after stopping the driving machine. This part of the diagram (after stopping the driving machine) is used to set the mechanical characteristics of steel ropes (harmonic oscillations).

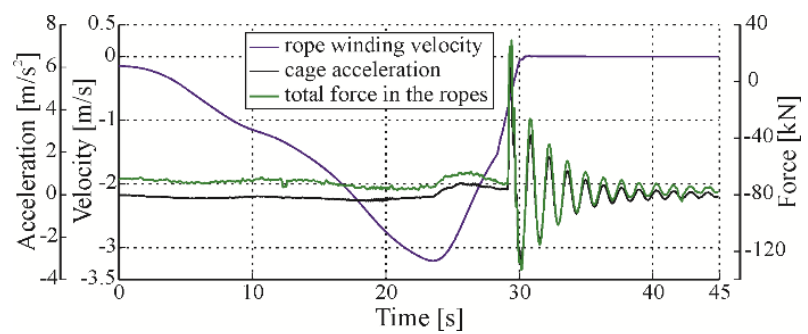

Figure 10: Diagram with the results obtained during lowering an empty cage and sudden stopping, at a "high" velocity (I motion case)

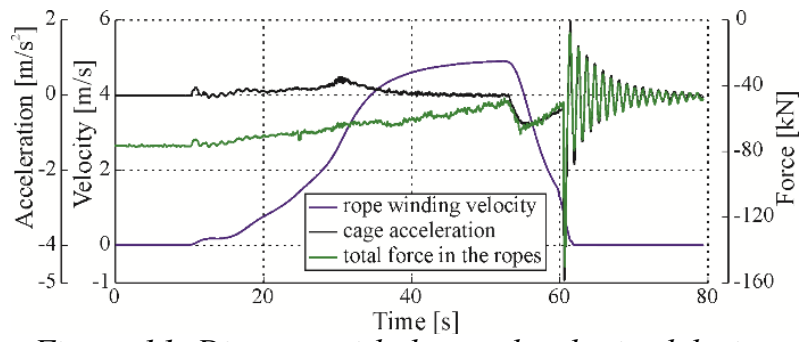

Figure 11: Diagram with the results obtained during lifting the empty cage and sudden stopping, at a "high" velocity (II motion case)

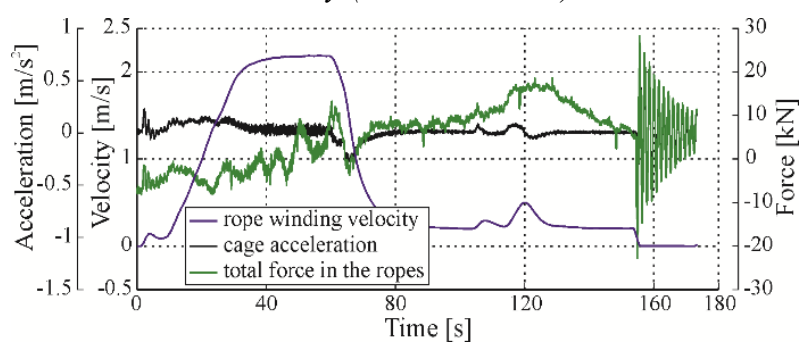

Figure 12: Diagram with the results obtained during the loaded cage lifting process (III motion case)

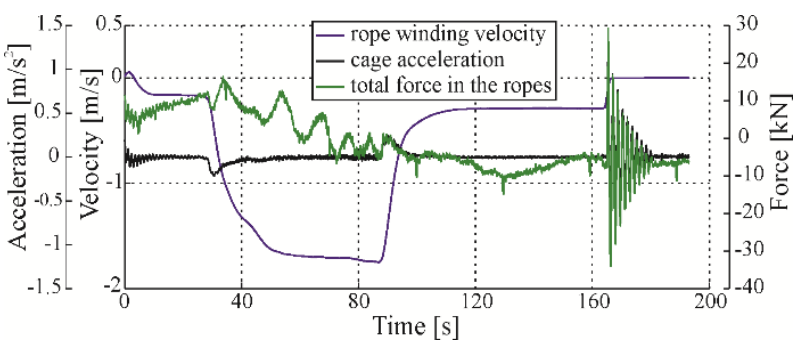

Figure 13: Diagram with the results obtained during loaded cage lowering process (IV motion case)

\subsection{Main dynamic parameters}

Stiffness is the basic parameter of oscillatory processes and it represents a feature of a material that defines the ratio between load and deformation. It is viewed as a constant matter in most oscillatory processes with small amplitudes and elements made of steel and similar materials [13]. On the other hand, it is a case with some materials also used in mechanical engineering that the feature is not linear, which brings to the occurrence of the so-called non-linear oscillations whose analysis is more complex on numerous levels. A specific case of nonlinearity happens at the lifting machines with steel ropes and it refers to the fact that the stiffness changes to gether with the change in the ropes' free lengths in the following relation:

$$
c(t)=\frac{E \cdot A}{L-l(t)}
$$

Apart from the variable stiffness, attention should be paid to the elasticity modulus $(\boldsymbol{E})$, which is much more difficult to define in comparison with the homogenous bodies since the steel rope is a complex structure, consisting of a large number of wires layered into strands, while the strands are stranded into a rope with the core made of steel or fibre.

There are different expressions mentioned in the literature, for its calculation depending on the wire elasticity modulus and the angles at which the wires lay into a strand, and strands into a rope. These expressions only give approximate data because the real magnitudes of the elasticity modulus, apart from the above mentioned parameters, depend on the stress magnitude, core material, time spent in service (the number of load cycles), types of wire connections etc.

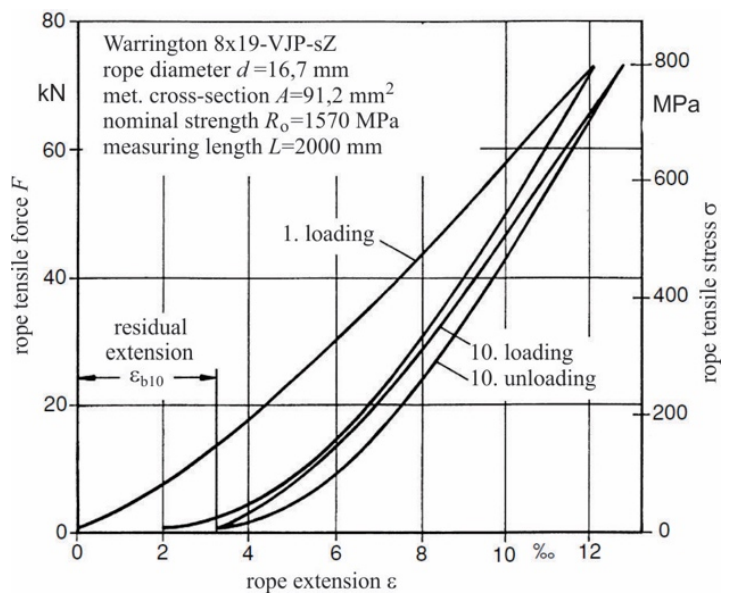

Figure 14: Stress-extension curves for new stranded wire ropes with fibre core, after 10 loadings, [14] 


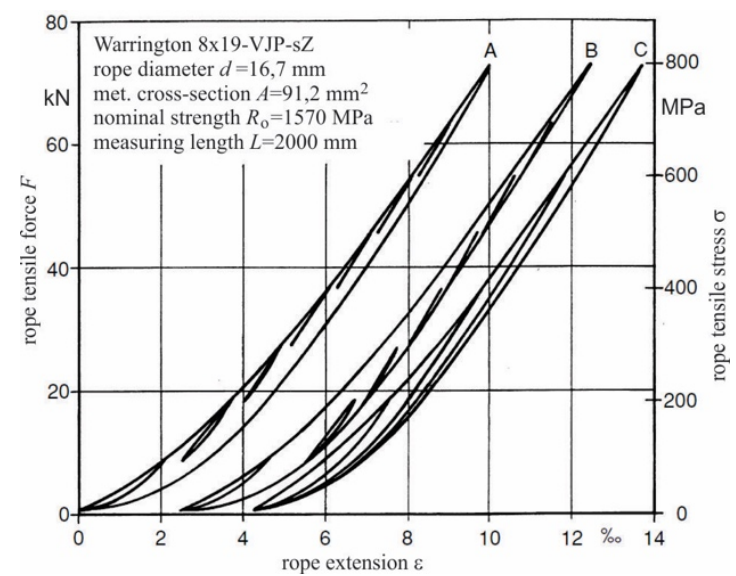

Figure 15: Stress-extension curves for new stranded wire ropes with fibre core, after 10 loadings for the difference stress levels, [14]

Fig. 14 and 15 show the experimental results [14] which show a noticeable difference in the results between the first loading of the rope (new rope), and after 10 loadings (Fig. 14), and also the effect of the stress level with the loading and unloading in Fig. 15.

Nevertheless, the application of the results generated in this way is disputable when it comes to dynamic processes. Adequate elasticity modulus values for the ropes in exploitation can be gained through direct measuring in the real working conditions of the elevator facilities.

Damping. In a lot of practical systems, oscillation energy is gradually transformed into heat or sound, the effect mostly known as damping. Despite the fact that the quantity of such energy is relatively small, it is important to dedicate some attention to damping in order to predict the oscillatory systems response, such as the elevator systems considered in this paper.

Damping at the elevator is complex and it happens because of the rope inner friction (viscous and hysteretic damping), Coulomb's friction on guide rails and damping due to the air flow around the cabin (cage) in the elevator shaft [8] and [10].

Since the presented experiment results (Tab. 2) refer to the moment of stopping the cage $(v=0)$, damping as a consequence of air flow around the cage can be neglected.

The friction on the elevator guide rails creates the damping force (Coulomb's friction) which is constant in its magnitude, but it is of the opposite direction compared to the motion of the oscillating load. Since this type of elevator requires special attention to be paid to the guiding accuracy and reducing the guide rails friction, in the example with centrical cabin load, the friction forces can be neglected in relation to the total load. Nevertheless, the influence can be of importance for cabin oscillation analyses.

The size of the impact caused by rope damping and damping due to guide rails friction is possible to define via "overlapping" of the diagram measurement results and simulation results, as presented in Fig. 16.

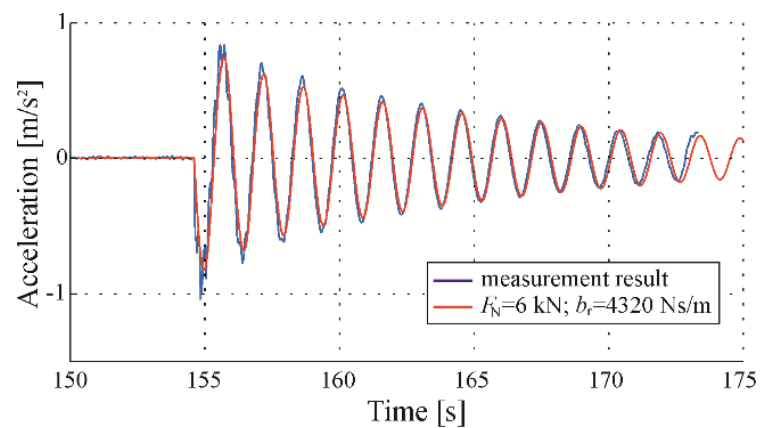

Figure 16: The impact of inner and Coulomb's friction on oscillating systems when $b=5161 \mathrm{Ns} / \mathrm{m}$ (Table 2)

Based on the theory about free harmonic damping oscillations, it is concluded that for determining the dynamic parameters, one should take the part of the cage oscillation diagram after the driving machine is stopped.

By measuring the amplitudes and oscillating periods of free damping oscillations (changes in cage acceleration), the damping coefficient $(\delta)$ can be determined via a logarithmic decrement, and based on this, a resistance force coefficient $(b)$ :

$$
\begin{gathered}
D=\ln \frac{x_{i}}{x_{i+1}}=\frac{1}{n} \ln \frac{x_{i}}{x_{i+n}}=\delta \cdot \tilde{T} \rightarrow \delta=\frac{D}{\tilde{T}} \\
b=2 \cdot \delta \cdot M_{\mathrm{e}}
\end{gathered}
$$

with:

$x_{i}, x_{i+1}$ and $x_{i+n}$ - measured oscillating amplitudes,

$\tilde{T}$ - measured oscillating period of free damping oscillations,

$M_{\mathrm{e}}=M+q \cdot \frac{1}{3} L(t)$ - reduced oscillating mass,

$M$ - total mass hanging on hoist ropes (loaded cage and compensation ropes),

$L(t)=L-\int v(t) \mathrm{d} t$ - hoist ropes' free length

$v(t)$ - circumferential velocity of the pulley (drum).

Determining the stiffness coefficient (c) and elasticity modulus $(E)$ of hoist ropes can be performed with the measured oscillation parameters (oscillating period, oscillating amplitudes, etc.):

$$
\begin{gathered}
c=M_{\mathrm{e}} \cdot \omega^{2} \\
E=\frac{c \cdot L}{A}
\end{gathered}
$$

with:

$$
\begin{aligned}
& \omega=\sqrt{\tilde{\omega}^{2}+\delta^{2}}-\text { circular frequency of free oscillations, } \\
& \tilde{\omega}=\frac{2 \pi}{\tilde{T}}-\text { damping oscillation frequency }
\end{aligned}
$$

Fig. 17 is an illustration of determining the said mechanical characteristics of hoist ropes based on the cage acceleration changes diagram (after the driving machine was stopped) in the III motion case. 


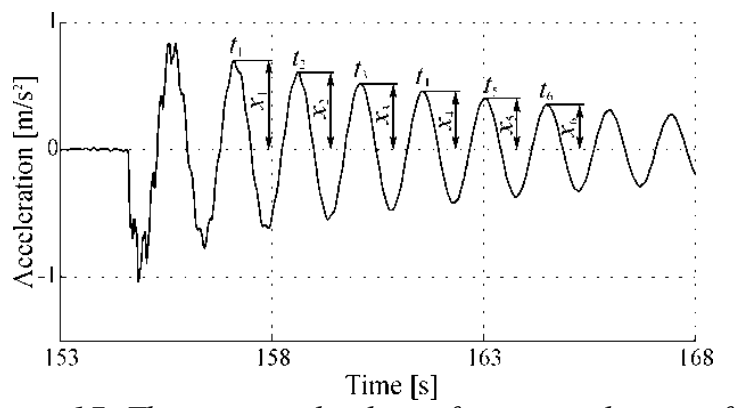

Figure 17: The measured values of cage acceleration for III motion case

Based on the diagram in Figs. 10 to 13 and the expressions (Eq. (9) and (12)), mechanical characteristic s of steel ropes are defined, as shown in Table 2. Upon analyzing the measured results, it can be concluded that the data for elasticity modulus are in agreement with the data from the literature [14]. The higher values of elasticity modulus for loaded cabins are seen as a consequence of the rope that was constructed by putting the lays of wires in strands, and strands into a rope. This confirms the validity of the applied procedure, enabling us to define the real (exploitation) values in mine elevators. The damping coefficient values, for which there is no significant comparative data, are not constant in size, but appear to be different in the analyzed experiments.

Table 2: Values obtained by measuring and parameters of hoistropes

\begin{tabular}{|c|c|c|c|c|c|c|c|c|}
\hline & $L[\mathrm{~m}]$ & $M_{\mathrm{e}}[\mathrm{kg}]$ & $\delta\left[\mathrm{s}^{-1}\right]$ & $\omega[\mathrm{rad} / \mathrm{s}]$ & $c[\mathrm{~N} / \mathrm{m}]$ & $b[\mathrm{Ns} / \mathrm{m}]$ & $E[\mathrm{MPa}]$ & $\delta / \omega$ \\
\hline I (Fig 9a) $\downarrow$ & 409 & 18797 & 0.33 & 4.67 & 409163 & 12222 & 98440 & 0.070 \\
\hline II (Fig. 9b) $\uparrow$ & 266 & 20525 & 0.21 & 5.69 & 663329 & 8718 & 103792 & 0.037 \\
\hline III (Fig. 9c) $\uparrow$ & 413 & 28099 & 0.09 & 4.26 & 510803 & 5161 & 124095 & 0.022 \\
\hline IV (Fig. 9d) $\downarrow$ & 536 & 26613 & 0.18 & 3.88 & 401206 & 9639 & 126498 & 0.047 \\
\hline
\end{tabular}

\subsection{Computer simulations results}

In order to simulate the mine elevator operation process, the study has set the change in hoisting rope velocity at the point of winding onto the driving drum as the change (diagram), obtained by direct measuring on the driving machine via an incremental encoder (pos. 9, Fig. $6)$.

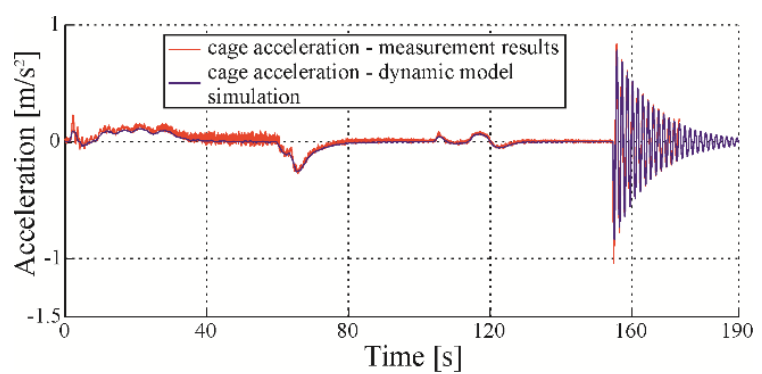

Slika 18: Cage acceleration diagrams in the motion case III (Fig. 9c)

An oscillation diagram was separated with the purpose of verifying the dynamic model during the whole period while the cage was moving, as well as after the complete stop in the driving machine moving. The acceleration diagram in the III motion case is shown, "overlapping" the diagram with the measured results, Fig. 18.

Judging by the diagram in Fig. 18, it can be concluded that the dynamic model with dynamic parameters, determined by the measuring with satisfactory accuracy, shows the real behavior of a mine elevator. As a result, this makes computer simulations possible, which will analyze the real loads of the exploitation facility [7]. The described method is a new approach that will en sure the analysis of dynamic behavior in systems for vertical hoisting, which can be found in exploitation.

As an illustration of the possibility of dynamic analysis, the following section shows diagrams that represent changes in individual values. They were created in specialized software for dynamic analysis, MSC ADAMS, using the experimental data shown in Table 2.

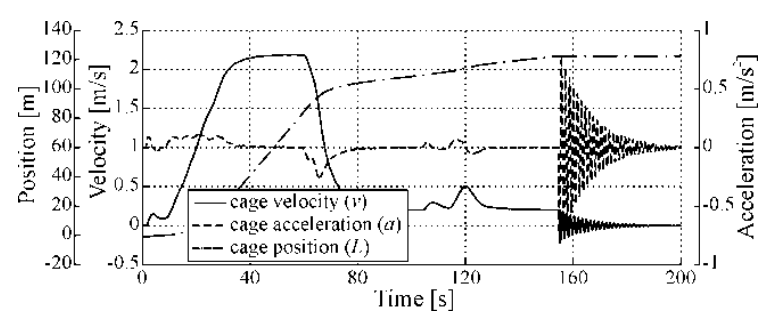

Figure 19: Diagram showing the changes in cage position, velocity, and acceleration, for III motion case

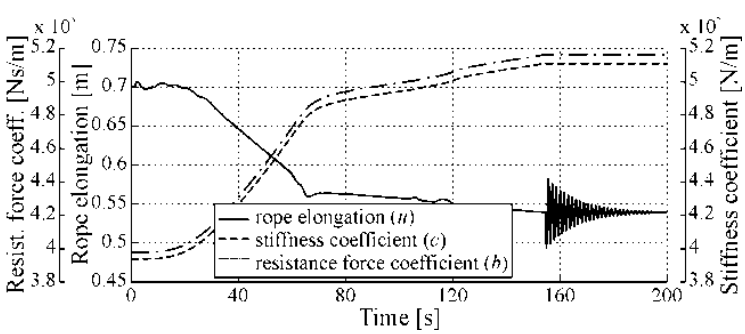

Figure 20: Comparative diagrams showing the changes in the elongation, stiffness coefficient, and resistance force coefficient of hoist ropes, for III motion case

\section{CONCLUSION}

The paper presents an experimental method that can be used to determine dynamic parameters such as stiffness, elasticity modulus, and damping in exploited elevator steel ropes. Certain elasticity modulus values that are presented in Tab. 2 reveal the noticeable dependence on the load, i.e. rope stress. In addition, the damping coefficient in ropes is not a constant size, but it depends on the position of a cage. It can be deduced that ropes experience a combination of viscous damping and hysteretic damping, which should be further investigated in these systems.

Mine elevators are used in the mines with underground exploitation at the depths as deep as $2000 \mathrm{~m}$ with the carrying capacity of maximum $30 \mathrm{t}$ and the lifting velocities up to $20 \mathrm{~m} / \mathrm{s}$. Therefore, their analysis is of special interest because they define the quality basis for optimal projecting and their maintenance in relatively heavy working conditions. 
Apart from the mentioned extreme parameters, the complexity of the dynamic analysis of these facilities is primarily due to these facts:

- The basic model is an oscillatory problem with an infinite number of DOF and it is influenced by a large number of factors.

- The driving torque is a variable value (the function of the pulley rotational speed and the operating load).

- The stiffness of the wire rope varies with the changes in the cage position, causing parametric oscillations.

- Steel rope elasticity modulus is not a constant value, as it is the case with homogenous bodies. It depends on rope structure, stress level and how long the rope was in service.

- Damping in the wire rope is a feature which has not been sufficiently examined. It is a consequence of the inner friction of a hysteretic type, depending on the construction of the rope, stress in the rope, contact type and friction between the wires, then lubrication, oscillation amplitudes etc.

- The influence of friction in the guide rails on the damping of the whole system cannot be ignored.

\section{REFERENCES}

[1] Q. Peng, P. Xu, H. Yuan, H. Ma, J. Xue, Z. He, S. Li, „Analysis of Vibration Monitoring Data of Flexible Suspension Lifting Structure Based on Time-Varying Theory“, Sensors, Vol.20(22), pp.6586, (2020)

[2] Q. Zhang, Y. Yang, T. Hou, R. Zhang, „Dynamic analysis of high-speed traction elevator and traction carrope time-varying system", Noise \& Vibration Worldwide, Vol. 50(2), pp. 37-45,(2019)

[3] J. Bao, P. Zhang, C. Zhu, ,Modeling of Rope Longitudinal Vibration on Flexible Hoisting System with Time-Varying Length", Applied Mechanics and Materials, Vol. 130-134,pp. 2783-2788,(2011)

[4] X. Arrasate, S. Kaczmarczyk, G. Almandoz, J. M. Abete, I. Isasa, ,The modelling, simulation and experimental testing of the dynamic responses of an elevator system", Mechanical Systems and Signal Processing, Vol. 42(1-2), pp. 258-282, (2014)

[5] I. Herrera, H. Su, S. Kaczmarczyk, ,Investigation into the damping and stiffness characteristics of an elevator car system“", Applied Mechanics and Materials, Vol. 24-25, pp. 77-82,(2010)

[6] S. Watanabe, T. Okawa, ,Vertical vibration of elevator compensating sheave due to brake activation of traction machine", Journal of Physics: Conference Series, Vol. 1048(012012), (2018)

[7] R. Đokić, „Dynamics researching and development of vertical transport machines using numerical-experimental procedures", PhD thesis, University of Novi Sad (Serbia), (2016)

[8] J. Vladić, M. Jovanović, R. Đokić, M. Kljajin, M Karakašić, ,Theoretical and experimental analysis of elevator dynamic characteristics“, Tehnički vjesnik / Technical Gazette, Vol. 22(4), pp. 1011-1020,(2015)

[9] J. Vladić, R. Đokić, M. Kljajin, M. Karakašić, „Modelling and simulations of elevator dynamic behaviour", Tehnički vjesnik / Technical Gazette, Vol. 18(3), pp. 423-434,(2011)

[10] S. S. Rao, „Mechanical vibrations“, Prentice Hall, Upper Saddle River(USA), (2011)

[11] A. Sinha, ,Vibration of Mechanical Systems“, Cambridge University Press, Cambridge (England), (2010)

[12] O. A. Goroshko, ,Evolution of the dynamic theory of hoist ropes", International Applied Mechanics, Vol. 43(1), pp. 64-67,(2007)

[13] J. Vladić, R. Đokić, M. Jovanović, „Steel wire rope and computational-experimental procedures for the analysis of specific transport machines", University of Novi Sad, Faculty of Technical Sciences, Novi Sad (Serbia), (2019)

[14] K. Feyrer, ,Wire Ropes“, University of Stuttgart, Stuttgart (Germany), (2007)

\section{Analiza dinamičkih parametara liftova sa rešenjem zbirne akvizicije podataka tokom eksperimentalnih istraživanja}

Radomir Đokić1 ${ }^{*}$, Jovan Vladić1 ${ }^{\text {, Dragan Živanić }}{ }^{1}$, Tanasije Jojić ${ }^{1}$, Vesna Jovanović ${ }^{2}$, Nebojša B. Zdravković ${ }^{3}$

${ }^{1}$ Fakultet tehničkih nauka Univerziteta u Novom Sadu, Srbija

${ }^{2}$ Mašinski fakultet Univerziteta u Nišu, Srbija

${ }^{3}$ Mašinsko-građevinski fakultet u Kraljevu, Univerzitet u Kragujevcu, Srbija

Modeliranje dinamičkog ponašanja liftova sa velikim brzinama dizanja (savremeni liftovi $u$ građevinarstvu i rudnički liftovi) je složen zadataki važan korak u procesu projektovanja i stvaranja uslova za bezbednu i pouzdanu eksploataciju ovih mašina. Zbog velikih visina i brzina dizanja, standardne procedure za dinamičku eksploataciju nisu adekvatne. U cilju identifikacije osnovnih parametara dinamičkog modela (krutost i prigušenje), primenjena je jedinstven a metoda, zasnovana na eksperimentalnim merama za lift. Zbog provere ovog postupka, eksperiment je sproveden na rudničkom liftu u RTB Bor, Srbija. Na osnovu dobijenih računsko-eksperimentalnih rezultata prikazane su simulacije dinamičkog ponašanja praznog i napunjenog kaveza.

Ključne reči: Mehaničke karakteristike čeličnih užadi, Prikupljanje podataka, Eksperimentalna istraživanja 